\title{
Examining Value Co-Destruction: Toward a Typology of Resource Disintegration: An Abstract
}

\author{
Joanne T. Cao, Bruce L. Alford, and Nina Krey
}

\begin{abstract}
The notion of consumer misbehavior has gained more attention in recent years, challenging the old adage that "the customer is always right." This is also evident in the value co-creation literature in which certain behaviors, such as consumer participation, may result in undesired consequences. However, only a handful of researchers have begun to view this alternative side to value co-creation. As such, this article seeks to gain a better understanding of the manifestations and traits of value co-destruction (VCD), the opposite possibility of value co-creation. Here, VCD refers to the decline in value created together by a provider and consumer from their interactions and experiences that result in resource disintegration. From a service-dominant logic perspective, the current study argues the propensity of consumers contributing negative value to the co-creation process through resource disintegration. That is, if resources are misused or applied the wrong way, then the value potential is not realized from the dyad. Using a typology of value destruction, this article explores the application of resource disintegration based on the interaction between service systems and intentionality.
\end{abstract}

\author{
J.T. Cao $(\bowtie)$ \\ University of Southern Mississippi, Hattiesburg, MS, USA \\ e-mail: joanne.cao@usm.edu \\ B.L. Alford \\ Louisiana Tech University, Ruston, LA, USA \\ e-mail: balford@latech.edu \\ N. Krey \\ Rowan University, Glassboro, NJ, USA \\ e-mail: krey@ rowan.edu
}

